\title{
PRÁTICAS DO CUIDADO DE SI NA PREVENÇÃO DAS IST REALIZADAS POR TRAVESTIS E MULHERES TRANSEXUAIS, EM CURITIBA E PONTA GROSSA, PARANÁ
}

\section{SELF CARE PRACTICES IN THE PREVENTION OF STIS PERFORMED BY TRANSVESTITES AND TRANSSEXUAL WOMEN, IN CURITIBA AND PONTA GROSSA, PARANÁ}

\author{
Ramon de Oliveira Bieco Braga \\ Universidade Estadual de Ponta Grossa, Ponta Grossa, PR, Brasil \\ ramonbieco@hotmail.com \\ Marcio José Ornat \\ Universidade Estadual de Ponta Grossa, Ponta Grossa, PR, Brasil \\ geogenero@gmail.com
}

\begin{abstract}
RESUMO
Nesta pesquisa problematizamos 'quais são as práticas do cuidado de si executadas por travestis e mulheres transexuais, na prevenção das Infecções Sexualmente Transmissíveis (IST), nos municípios de Curitiba e Ponta Grossa, Paraná?'. Para responder à questão central, utilizamos a técnica de coleta de dados entrevista semiestruturada e entrevistamos 20 pessoas que se auto identificam como travestis e mulheres transexuais, nos municípios de Curitiba e Ponta Grossa, Paraná. Estas entrevistas ocorreram com base na técnica estatística de amostragem Snowball (GOODMAN, 1961) e foram analisadas com base na técnica de análise de discurso (BARDIN, [1977] 2016). Com base na literatura Queer e nas reflexões das Geografias das Sexualidades, compreendemos que o uso de preservativo e a realização de exames, são práticas do cuidado de si que compõe a relação saúde e doença dos corpos de travestis e mulheres transexuais. Embora em alguns casos tenha ocorrido a infecção do HIV/AIDS e demais IST, constatou-se que entre o grupo de travestis e mulheres transexuais entrevistadas, a prática do uso de preservativos aliado ao PrEP, se constituem como as práticas do cuidado de si na prevenção das IST.
\end{abstract}

Palavras-chave: Cuidado de Si. Travestilidades. Transexualidades.

\begin{abstract}
In this research we problematize 'what are the self-care practices performed by transvestites and transsexual women, in the prevention of Sexually Transmitted Infections (STIs), in the municipalities of Curitiba and Ponta Grossa, Paraná?'. To answer the central question, we used the semi-structured interview data collection technique and interviewed 20 people who identify themselves as transvestites and transsexual women, in the municipalities of Curitiba and Ponta Grossa, Paraná. These interviews took place based on the statistical technique of Snowball sampling (GOODMAN, 1961) and were analyzed based on the discourse analysis technique (BARDIN, [1977] 2016). Based on the Queer literature and the reflections of the Geographies of Sexualities, we understand that condom use and examinations are self-care practices that make up the relationship between health and disease of transvestite bodies and transsexual women. Although in some cases there was HIV/AIDS infection and other STIs, it was found that among the group of transvestites and transsexual women interviewed, the practice of condom use combined with PrEP, constitute as the practices of self-care in the prevention of STIs.
\end{abstract}

Keywords: Self-Care. Travestilities. Transsexualities.

Recebido em: 19/12/2021

Aceito para publicação em: 21/12/2021.

$\begin{array}{lllll}\text { Hygeia Uberlândia - MG } \quad \text { Edição especial: X GeoSaude } \quad \text { Fev./2022 } & \text { p. 23-33 Página } 23\end{array}$




\section{INTRODUÇÃO}

Esta pesquisa problematizou 'quais são as práticas do cuidado de si executadas por travestis e mulheres transexuais, na prevenção das Infecções Sexualmente Transmissíveis (IST), nos municípios de Curitiba e Ponta Grossa, Paraná?'.

Salientamos que esta questão central compõe a pesquisa de doutoramento em Geografia (BRAGA, 2020), desenvolvida no âmbito do Grupo de Estudos Territoriais (GETE) da Universidade Estadual de Ponta Grossa (UEPG), onde temos refletido geograficamente sobre a relação saúde e doença do corpo da população de travestis e mulheres transexuais (BRAGA, 2017; BENATO; BRAGA, 2019; BRAGA; ORNAT, 2019; BRAGA; ORNAT, 2020). Destacamos ainda que temos estabelecido diálogos com as Organizações Não Governamentais (ONG's) Transgrupo Marcela Prado em Curitiba/PR e Renascer em Ponta Grossa/PR, que trabalham com a promoção da saúde da população de travestis e transexuais. Portanto, a nossa reflexão teórica se apresenta situada nos municípios de Curitiba/PR e Ponta Grossa/PR.

Destarte, a realização desta pesquisa se justifica por corroborar com a inteligibilidade das práticas do cuidado de si e promoção da saúde de parte da população brasileira, isto é, travestis e mulheres transexuais que tem sido estigmatizada como corpos que se prostituem (SILVA, ([1993] 2007; KULICK, 2008), circunscritas em práticas de violências como assaltos e consumo de drogas (PELÚClO, 2009).

Entretanto, ressalva-se que as travestis e mulheres transexuais possuem corpos ininteligíveis pela cisheteronormatividade, que consiste em um sistema social que normatiza as relações sociais. Para a cisheteronormatividade, os corpos saudáveis são os corpos que possuem relações sexuais heterossexuais e, para Butler ([2003] 2016), apresentam uma linearidade entre sexo, gênero e desejo. Portanto, todos os corpos que não correspondem a essa linearidade, são desqualificados e marginalizados pela cisheteronormatividade, como ocorre com os corpos de travestis e mulheres transexuais.

De acordo com dados divulgados pela ONG interacional Transgender Europe (TGEU, 2017), o Brasil é o país mais violento para as travestis e mulheres transexuais, pois é o país onde mais se mata essas pessoas. Somente em 2019, 124 travestis e transexuais foram assassinadas no Brasil em decorrência da travestifobia e transfobia que é a aversão as travestis e transexuais (ANTRA, 2020).

Nesse sentido, Benedetti (2005) e Ornat (2011) identificaram que a violência incidente nestes corpos não é somente a física, pois elas também são vítimas das violências psicológicas, sobretudo quando são expulsas da casa dos familiares, não são bem-vindas nos espaços escolares e devido à baixa escolaridade, se prostituem para poder sobreviver.

Assim, reconhecendo que o estado de saúde dos corpos das travestis e mulheres transexuais é comprometido em decorrência da violência que incide sob estes corpos, nesta pesquisa elegeu-se como objetivo compreender quais práticas do cuidado de si são executadas por elas, no tocante a prevenção das IST.

\section{OPERACIONALIZAÇÃO}

Para responder à questão problematizadora 'quais são as práticas do cuidado de si executadas por travestis e mulheres transexuais, na prevenção das Infecções Sexualmente Transmissíveis (IST), nos municípios de Curitiba e Ponta Grossa, Paraná?', foi realizado entrevistas com 20 pessoas que se auto identificam como travestis e mulheres transexuais. Estas pessoas foram entrevistadas entre os dias 17 de janeiro de 2017 a 23 de abril de 2017, com o auxílio das ONG's Transgrupo Marcela Prado em Curitiba/PR e Renascer em Ponta Grossa/PR.

Considerando que a fonte primária dos dados foram as travestis e mulheres transexuais auto identificadas, torna-se imperativo mencionar que para acessar o grupo de estudo, utilizamos a técnica estatística de amostragem Snowball (GOODMAN, 1961), que consiste na identificação de uma pessoa que compõe o grupo e indica outras pessoas do mesmo grupo, conforme a sua rede de pessoas conhecidas. Para esta técnica de amostragem, o campo satura a partir do momento que nas entrevistas não é possível mais identificar novas informações. Logo, o campo deve ser concluído. Portanto, durante a realização do campo, foi possível verificar que o campo saturou na $15^{\mathrm{a}}$ entrevista e optamos em realizar mais 5 entrevistas porque elas já estavam agendadas e também precisávamos ratificar que 0 campo estava saturado, o que de fato foi constatado.

\begin{tabular}{lllll}
\hline Hygeia Uberlândia - MG $\quad$ Edição especial: X GeoSaude & Fev./2022 & p. 23-33 & Página 24
\end{tabular}


Posterior a realização das entrevistas que tiveram o áudio gravado mediante autorização das entrevistadas, o conteúdo foi transcrito com auxílio do software Microsoft Word 2016 e sistematizado em evocações semânticas com auxílio do software LibreOffice Base. Neste último software mencionado, as evocações foram sistematizadas conforme a espacialidade discursiva e as categorias discursivas, que subsidiaram a aplicação da técnica de análise de discurso (BARDIN, [1977] 2016).

Neste artigo, é realizado uma análise da espacialidade discursiva do 'corpo' (que corresponde a 39\% do volume total de evocações das entrevistas) que, conforme é indicado no Gráfico 01, apresentou as categorias discursivas 'cuidado de si' (27\%), 'identidade' (20\%), 'doença' (19\%), 'saúde' (17\%), 'cirurgia' $(7 \%)$, 'sentimento' (4\%), 'prevenção de doenças' (2\%), dentre outras categorias (4\%).

\section{Gráfico 01 - Categorias discursivas da espacialidade corpo.}

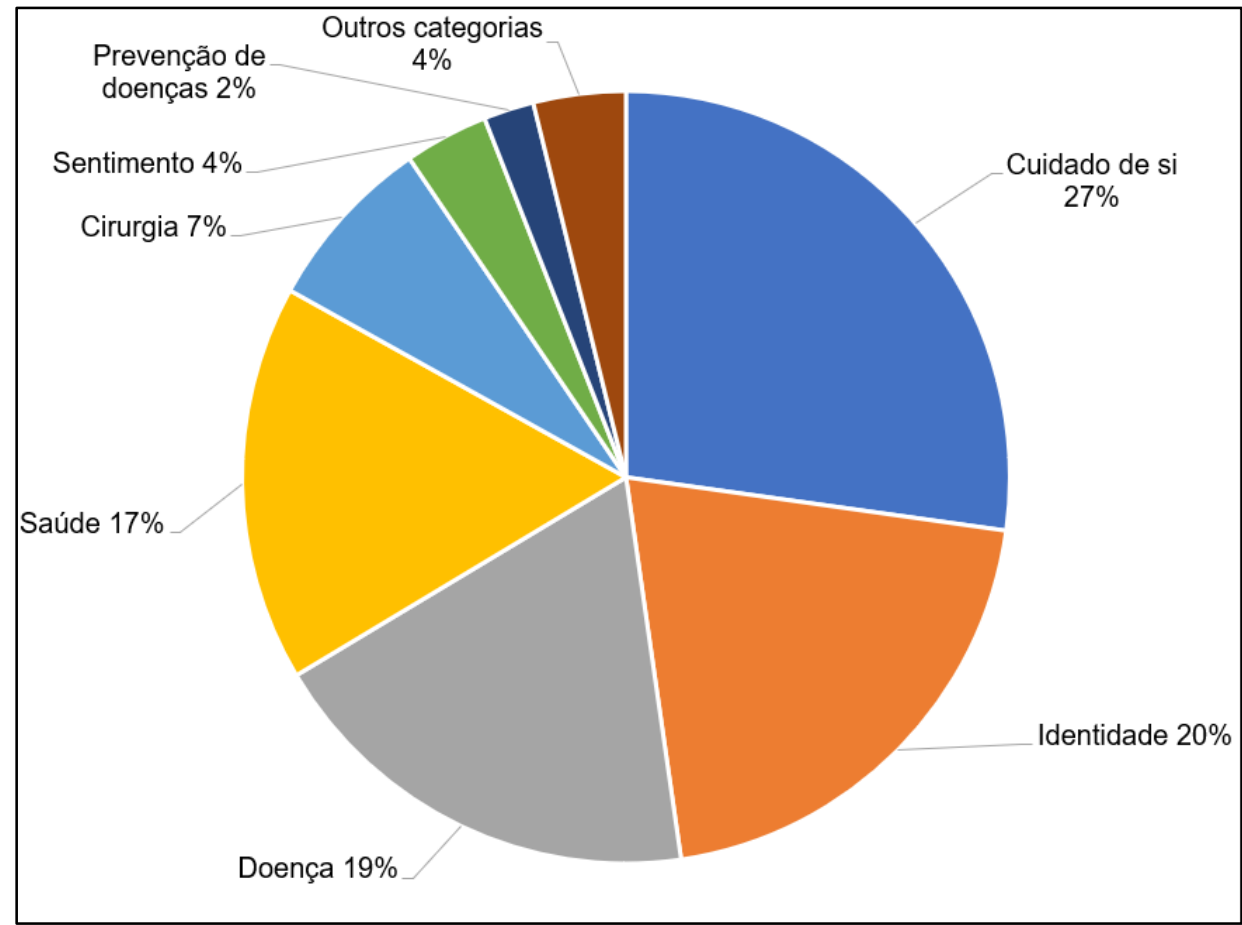

Fonte: Entrevistadas (2017). Elaborado por Ramon O. B. Braga (2020).

Ao que concerne a categoria discursiva 'cuidado de si' $(27 \%)$, foi possível identificar evocações sobre o uso de 'preservativo' (41,6\%), 'automedicação' (19,5\%), 'exames' (13\%), 'alimentação' (6,5\%), 'internet' $(5,2 \%)$, 'estética' $(3,9 \%)$, 'chá' $(3,9 \%)$, dentre outras evocações $(6,5 \%)$. Salientamos que para este artigo, realizamos a análise das categorias discursivas 'preservativo' $(41,6 \%)$ e 'exames' $(13 \%)$, pois existe uma relação em praticar o cuidado de si com o uso de preservativo para prevenir as IST, bem como realizar exames de sangue para verificar se o corpo possui ou não alguma IST.

\section{AS PRÁTICAS NO CUIDADO DE SI DO CORPO DAS TRAVESTIS E MULHERES TRANSEXUAIS}

Para iniciar a apresentação dos resultados e discussões sobre o corpo e as práticas do cuidado de si, torna-se necessário contextualizar como o termo cuidado de si tem sido trabalhado por algumas pesquisas sobre gênero, sexualidades, travestilidades e transexualidades. Portanto, nesta pesquisa, compartilha-se da compreensão do termo cuidado de si apropriada por Peres (2008), Silva, et. al. (2009), Ventura e Schramm (2009) e Sarti (2010).

Segundo Peres (2008), na população de travestis e mulheres transexuais, as práticas do cuidado de si correspondem a um conjunto de habilidades e/ou atividades ligadas ao cuidado com a estética, saúde, bem-estar físico e psicológico do corpo. O autor demonstra que essas práticas sociais são aprendidas com outras travestis e mulheres transexuais conhecidas. As práticas envolvem como, por exemplo, o consumo dos hormônios, o cuidado com o cabelo, com as unhas e o uso adequado de preservativo.

$\begin{array}{llllll}\text { Hygeia Uberlândia - MG } \quad \text { Edição especial: X GeoSaude } & \text { Fev./2022 } & \text { p. 23-33 Página } 25\end{array}$


Nessa perspectiva, o cuidado de si não deve ser compreendido como uma prática que ocorre somente nas espacialidades formais de saúde assistidas pelo Sistema Único de Saúde (Unidades de Saúde), pois elas realizam o cuidado de si com práticas que não estão diretamente circunscritas a esses espaços.

Nesta pesquisa, conforme pode ser verificado na Figura 01, reconhece-se o corpo como um espaço que compõe a microescala na vivência espacial. É com o corpo que as travestis e mulheres transexuais transitam em discrepantes escalas por outras espacialidades públicas ou privadas. Logo, o cuidado de si, assim como o corpo, também possui uma abordagem multiescalar. Compreende-se que as práticas da microescala do cuidado de si, são quando as travestis e mulheres transexuais cuidam do próprio corpo, enquanto que as práticas da meso e macroescala se concentram em como o corpo delas é cuidado por outras pessoas nos espaços formais de saúde, nas espacialidades da casa, da escola, do trabalho, dentre outras escalas espaciais. As práticas do cuidado do corpo das travestis e mulheres transexuais são singulares quando são elas que realizam o cuidado de si e mudam quando são os(as) profissionais de saúde que cuidam dos seus corpos e/ou quando são seus familiares, amigos(as), namorados(as), etc., que cuidam dos seus corpos. O cuidado desses corpos, pode ocorrer com afeto, carinho, respeito e humanidade, bem como pode ocorrer com desafeto, transfobia, violência e agressão.

Figura 01 - Escalas espaciais (corpo, casa, escola, espaços formais de saúde, trabalho, lazer e cidade) e as práticas do cuidado si, executadas por travestis e mulheres transexuais.

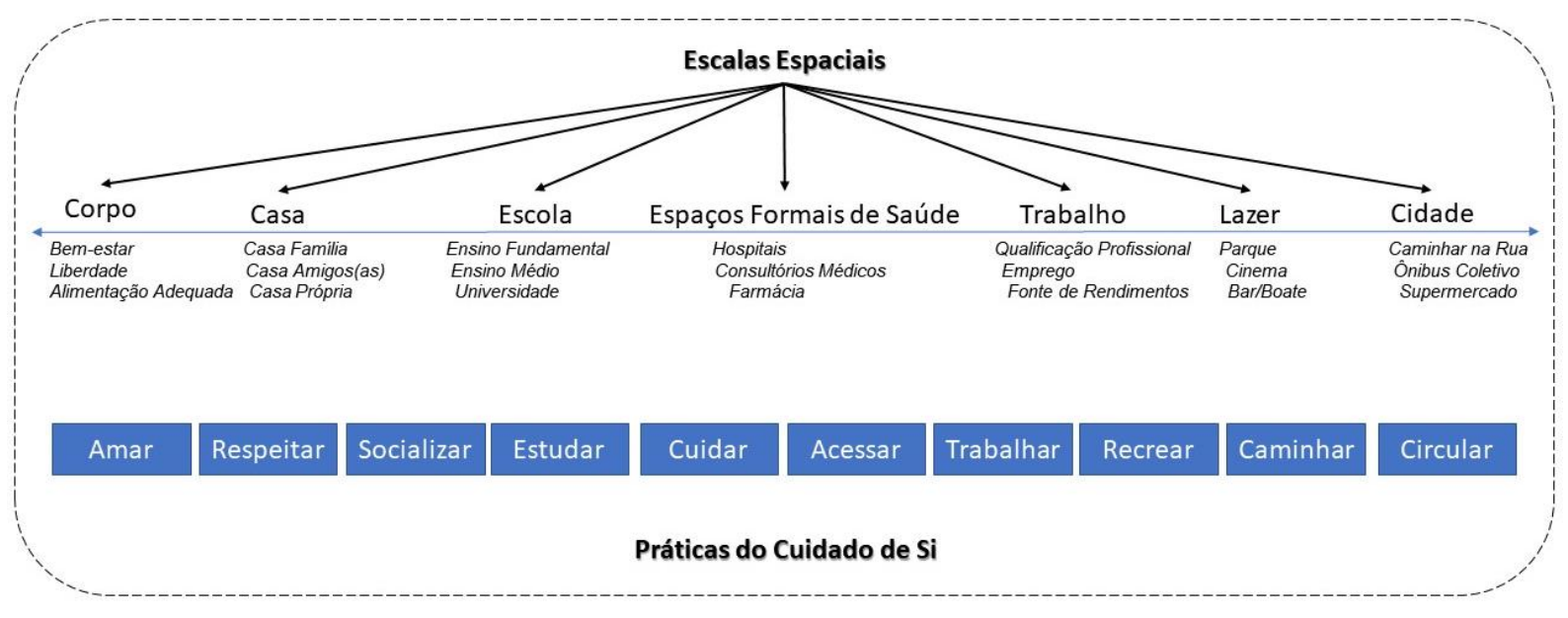

Fonte: Entrevistadas (2017). Elaborado por Ramon O. B. Braga (2020).

Para auxiliar na inteligibilidade do termo cuidado de si, Silva, et. al. (2009) discorrem que uma pessoa realiza o cuidado de si quando ela reproduz as práticas como, nas palavras das autoras, "(...) descansar, comer adequadamente, fazer exercício regularmente, dançar, caminhar, abraçar, beijar, cantar, orar, trabalhar criativamente, ter relacionamentos saudáveis, entre outras" (SILVA, et. al., 2009, p. 701). Logo, com base nessa reflexão, a análise das práticas do cuidado de si executadas pelas travestis e mulheres transexuais, deve reconhecer todas essas práticas e/ou atividades realizadas no espaço, sob discrepantes escalas.

Diante desse cenário, de acordo com Ventura e Schramm (2009), a execução das habilidades, práticas e/ou atividades do cuidado de si, se apresenta consubstanciado com a autonomia que o corpo das travestis e mulheres transexuais possuem em tomar a decisão de como, quando e em quanto tempo vão descansar/dormir. Quando e como vão se alimentar e se exercitar. Quando e com quem vão se relacionar afetivamente. Onde vão trabalhar e que ofício vão executar. Assim sendo, a autonomia em decidir como e quando elas executam o cuidado de si, pode ser fragilizada quando elas são expulsas de casa, quando lhes é interditado o acesso e permanência nos espaços formais de saúde, da escola e do mercado de trabalho.

Com base nas reflexões desenvolvidas por Ventura e Schramm (2009), é possível compreender que o cuidado de si, para as travestis e transexuais, perpassa pela microescala do corpo que para a

\begin{tabular}{lllll}
\hline Hygeia Uberlândia - MG & Edição especial: X GeoSaude & Fev./2022 & p. 23-33 Página 26
\end{tabular}


sociedade heteronormativa, não reconhece os seus corpos como normais e saudáveis. Logo, para a heteronormatividade, o corpo das travestis e transexuais são corpos anormais e patológicos, pois são corpos femininos que possuem pênis (mulheres transexuais) ou são corpos masculinos que possuem vagina e peito (homens transexuais). Como consequência, o discurso médico/biológico patologiza esses corpos e apresenta a prerrogativa de que as mesmas devem executar as cirurgias de transgenitalização como 'correção do sexo em relação ao gênero'. Todavia, as autoras demonstram que nem todas as travestis e transexuais desejam realizar a cirurgia de redesignação sexual, em decorrência do medo da morte, do sofrimento, do arrependimento ou pelo simples fato de não desejarem a cirurgia. $O$ posicionamento das travestis e mulheres transexuais em não desejarem realizar a cirurgia, posiciona os seus corpos a ininteligibilidade social do cânone heteronormativo, que não reconhece as travestilidades e transexualidades como normais e saudáveis. As autoras problematizam que muitas pessoas possuem o preconceito de que todas as travestis e transexuais buscam nos espaços formais de saúde, somente meios para realizar as intervenções cirúrgicas, e isso é uma inverdade. Pelo contrário, elas acessam os espaços formais de saúde para buscarem realizar exames médicos e/ou consultarem com clínico geral, endocrinologista, oftalmologista, psicólogos, psiquiatras, otorrinolaringologista, dentre outras especialidades médicas.

As questões levantadas por Ventura e Schramm (2009), se apresentam articuladas com os princípios do SUS, em relação ao cuidado da saúde, pois cada pessoa é responsável pelo cuidado de si, bem como toda a sociedade é responsável pelo cuidado do outro corpo humano, incluindo as pessoas que trabalham como profissionais dos serviços de saúde e as pessoas que não trabalham como profissionais dos serviços de saúde. Portanto, ao se refletir sobre o cuidado do corpo das travestis e mulheres transexuais, torna-se imperativo compreender que os seus corpos precisam ser respeitados por toda a sociedade, independente da escala e espacialidade, e esse corpo deve ser cuidado por elas mesmas, que precisam se sentir seguras, felizes, bem alimentadas, descansadas e dispostas a se exercitarem; e toda a sociedade é responsável por assegurar que as travestis e mulheres transexuais possam ter a autonomia em realizar o cuidado de si.

De acordo com Sarti (2010), a relação saúde/doença se apresenta consubstanciada no corpo. É no corpo que se materializam as práticas e/ou atividades no cuidado de si. Nesse contexto, o corpo das travestis e mulheres transexuais transita entre a saúde e a doença. São saudáveis quando possuem o nome social respeitado, quando portam a passibilidade ${ }^{2}$ e não experienciam a transfobia, quando possuem o direito assegurado a frequentarem e concluírem um curso profissionalizante, quando fazem o adequado consumo dos hormônios e se sentem bem com a estética feminina do corpo. No contrário, seus corpos vivenciam a doença quando elas experienciam a transfobia, quando os seus corpos são ininteligíveis pela sociedade heteronormativa e quando elas experienciam a interdição espacial ${ }^{3}$.

As práticas e/ou atividades do cuidado de si, transitam entre três escalas: a escala do corpo, a escala dos espaços públicos/privados e a escala dos espaços formais de saúde. Elas coexistem e são vivenciadas fluidamente. Ao que concerne a escala espacial do corpo, as práticas do cuidado de si se apresentam no cuidado biológico enquanto prevenção e/ou tratamento das doenças; na auto aceitação da identidade de gênero travesti/mulher transexual e na orientação sexual; no cuidado com a estética e a corporificação das feminilidades com base na realização das intervenções cirúrgicas e no consumo dos hormônios. Simultaneamente a essas práticas, o cuidado do corpo das travestis e mulheres transexuais ocorre em outras escalas nos espaços públicos/privados que transitam pelas espacialidades na casa dos familiares, nas escolas, no mercado de trabalho, nos bares/boates, no comércio, na delegacia, etc., onde deve existir o respeito pelo nome social, a aceitação pela identidade de gênero não binária (travesti e mulher transexual), bem como deve existir políticas públicas que reconheçam esses corpos e torne os espaços públicos/privados inclusivos para o ingresso, circulação e/ou permanência dessas pessoas. No âmbito da escala dos espaços formais de saúde, o adequado

\footnotetext{
${ }^{2}$ A passabilidade foi um termo discutido por Pontes e Silva (2018) que demonstraram como uma travesti e/ou mulher transexual 'se passa por mulher cisgênero' no espaço. A passabilidade (re)qualifica o corpo das travestis e mulheres transexuais, fazendo com que elas não sofram com os estigmas de corporificarem identidades de gênero não binárias.

${ }_{3}^{3}$ Por possuírem corpos que se identificam com os gêneros não binários, Cabral, Silva e Ornat (2013) denunciam que as travestis e mulheres transexuais vivenciam constantemente uma interdição espacial no público e no privado, pois os seus corpos não são lidos e compreendidos pela sociedade heteronormativa. Para os autores, a interdição espacial não ocorre com base em uma placa que anuncia que é proibido uma travesti e/ou uma mulher transexual circular pelo espaço público/privado. O que na realidade existe, é um discurso preconceituoso velado nas práticas sociais dos maus tratos, olhares de canto e buchichos que fazem com que elas se sintam indesejadas, desconfortáveis, malvistas e sentem vontade de ir embora e não voltar mais na farmácia, no mercado, no restaurante, na rua, dentre outras espacialidades.
}

$\begin{array}{llllll}\text { Hygeia Uberlândia - MG } & \text { Edição especial: X GeoSaude } & \text { Fev./2022 } & \text { p. 23-33 } & \text { Página } 27\end{array}$ 
cuidado do corpo das travestis e mulheres transexuais deve ocorrer com base na acessibilidade aos serviços de saúde, humanização no atendimento médico e na realização das intervenções cirurgias e hormonioterapia (no cuidado com a estética do corpo).

Assim sendo, as práticas do cuidado de si do corpo das travestis e mulheres transexuais se apresentam assentadas em duas perspectivas, a biológica e a estética. A análise dos resultados foi sistematizada com base nessas perspectivas. Elas coexistem e estão simultaneamente presentes nas práticas do cuidado de si.

A análise das entrevistas se demonstrou que a relação saúde/doença e a prevenção das doenças se constituem com base nas compreensões que as travestis e mulheres transexuais possuem acerca da saúde e da doença, e como essas compreensões incidem nas práticas preventivas das doenças. Essas práticas se constituem na perspectiva biológica, pois almejam prevenir as doenças transmitidas por vírus como, por exemplo, Influenza, HIV, Sífilis, dentre outros. Diante do contexto apresentado, na sequência é realizado uma análise sobre as práticas do cuidado que si, executadas por travestis e mulheres transexuais, no tocante a prevenção as IST.

\section{PRÁTICAS NO USO DE PRESERVATIVO E REALIZAÇÃO DE EXAMES}

Segundo Peres (2008), as práticas do cuidado de si correspondem a um conjunto de habilidades e/ou atividades ligadas ao cuidado com a estética, saúde, bem-estar físico e psicológico do corpo. O autor demonstra que essas práticas sociais são aprendidas com outras travestis e mulheres transexuais conhecidas. As práticas envolvem como, por exemplo, o uso adequado de preservativo e a realização de exames de sangue. Nessa perspectiva, o cuidado de si não deve ser compreendido somente como uma prática que ocorre nas espacialidades formais de saúde, pois elas realizam o cuidado de si com práticas que não estão diretamente circunscritas aos espaços formais de saúde.

A prática do 'cuidado de si', referente ao uso do 'preservativo' $(41,6 \%)$, é uma prática orientada pelos(as) profissionais da saúde e também pelas profissionais que trabalham com a prevenção das Infecções Sexualmente Transmissíveis (IST) para a população de travestis e mulheres transexuais. Sobre as práticas do cuidado de si, para Ametista-real ${ }^{4}$ (44 anos, entrevista realizada em 24/01/2017) "Ah, eu acho que a prevenção [das IST], né? Preservativo. Eu acho que é isso. A gente faz trabalho de prevenção. Então, é o preservativo. Não tem o que pegar".

Nesse sentido, Duquesa, que assim como Ametista-real trabalha em uma ONG, observou que:

O nosso trabalho é direcionado em saúde. Então, a gente tem que incentivar mais a nossa população a aderir ao uso do preservativo, tanto as prostitutas, como os gays e como as travestis ou as transexuais. Eu acho que o preservativo é única maneira segura e mesmo assim não é totalmente segura, né? (DUQUESA, 53 ANOS, ENTREVISTA REALIZADA EM 24/01/2017).

A maioria das travestis previnem as IST, conforme indicado por Carneiro (2014), mediante o uso de preservativos, sobretudo nas relações em que ocorrem práticas associadas a penetração, independentemente se elas exercem o papel ativo ou passivo da relação. Contudo, nas práticas do sexo oral, algumas entrevistadas por Carneiro (2014) indicaram que nem sempre utilizam o preservativo e algumas relataram que, quando elas se prostituem, existem clientes que oferecem mais dinheiro pelo programa para realizarem 0 ato sexual sem preservativo e a maioria delas se demonstraram sensibilizadas em negar a proposta porque se preocupam com a saúde, evidenciando, portanto, uma prática no cuidado de si.

A prática do uso de preservativo nas relações sexuais é um dos elementos centrais na prevenção das IST, como foi destacado por Janeira: "se eu uso preservativo, estou prevenindo uma Infecção Sexualmente Transmissível, por exemplo, um HIV [ou] uma sífilis" (JANEIRA, 23 anos, entrevista realizada em 14/03/2017).

De acordo com o Ministério da Saúde (BRASIL, 2019b), é desejável o uso do preservativo durante as relações sexuais, para prevenir a infecção do HIV, da Sífilis, Gonorreia, Herpes, dentre outras IST.

Todavia, Janeira indicou que:

${ }^{4}$ As identidades das entrevistadas foram ocultadas por nomes de borboletas.

\begin{tabular}{lllll}
\hline Hygeia Uberlândia - MG & Edição especial: X GeoSaude & Fev./2022 & p. 23-33 & Página 28
\end{tabular}


Não existe só o preservativo [para prevenir as IST]. Inclusive, tem as profilaxias pósexposição, pré-exposição, práticas sexuais que nem necessariamente são 'penetrativas' (sic.), né? Então, acho que [...] camisinha, 'centrismo' (sic.), não é o melhor, né? Acho que [existe] a liberdade do sujeito pra fazer a gestão (JANEIRA, 23 ANOS, ENTREVISTA REALIZADA EM 14/03/2017).

A Profilaxia Pós-Exposição (PEP) mencionada por Janeira, corresponde a uma medida de urgência como estratégia de prevenção ao HIV, Hepatites e demais IST que, de acordo com o Ministério da Saúde (BRASIL, 2020a), consiste na administração medicamentosa de antirretrovirais para as pessoas que vivenciaram pelo menos uma das seguintes situações:

a) foram abusadas sexualmente;

b) se relacionaram sexualmente sem o uso de preservativo ou caso o preservativo tenha estourado durante a relação sexual; bem como

c) nos casos de acidentes ocupacionais, isto é, quando um profissional da saúde possui contato direto com algum material sanguíneo de um paciente.

Para as pessoas que vivenciaram alguma das situações expostas, o Ministério da Saúde orienta que elas procurem por uma unidade de saúde o mais rápido possível nas primeiras 72 horas, para iniciar a medicação, cujo processo dura 28 dias e as pessoas recebem um acompanhamento adequado pelos(as) profissionais de saúde (BRASIL, 2020a).

Além do PEP, Janeira mencionou a Profilaxia Pré-Expositiva (PrEP) que, como indicado pelo Ministério da Saúde (BRASIL, 2020b), é um comprimido composto pelas medicações 'tenofovir' e 'entricitabina', que deve ser consumido diariamente pela pessoa que compõe o grupo de risco e/ou vivencia pelo menos uma das seguintes situações:

a) Homens que fazem Sexo com outros Homens (HSM);

b) Travestis e/ou transexuais;

c) Pessoas que trabalham com a prostituição;

d) Pessoas que se relacionam sexualmente sem o uso de preservativo;

e) Pessoas que se relacionam sexualmente com uma pessoa portadora do vírus HIV e que não realiza tratamento;

f) Pessoas que fazem uso repetido do PEP; ou

g) Pessoas que apresentam frequentemente episódios de IST;

O consumo diário do PrEP auxilia o organismo a combater somente a infecção do vírus HIV. Portanto, o PrEP não previne as outras IST (BRASIL, 2020b). Entretanto, com base nas entrevistas realizadas, foi verificado que o método de prevenção as IST mais citado foi o preservativo.

Segundo Monarca, ela prioriza praticar o cuidado de si com o uso do preservativo nas relações sexuais durante o trabalho na prostituição. Porém, ela reconhece que alguns clientes realizam sexo oral nela sem preservativo, pois eles não gostam de usar o preservativo durante o sexo oral, bem como ela demonstrou que devido ao dinheiro, também realiza sexo oral no cliente sem preservativo:

Os caras não ligam de eu chupar eles com camisinha, mas eles ficam bravos se eu por uma camisinha no meu 'pau' (sic.), porque eles não querem chupar um 'pau' (sic.) com camisinha, né amor? Eu chupo com camisinha. Eu faço... mas mesmo sabendo que, [no] sexo oral, o risco de pegar a AIDS é mínimo, eu chupo [sem camisinha], mas por dinheiro entendeu? Mas eles chupam o meu 'pau' (sic.) sem camisinha, lambem meu ânus sem camisinha. Agora sexo em si, penetração, só com camisinha, sem chance (MONARCA, 37 ANOS, ENTREVISTA REALIZADA EM 22/04/2017).

O não uso do preservativo também foi relatado por Zebrinha, Borboleta-oitenta e Imperatriz-rosa. De acordo com Zebrinha (22 anos, entrevista realizada em 18/04/2017): "olha, eu não vou mentir pra você. Fazer sexo oral com preservativo, eu sou muito relaxada, e foi nisso que peguei a sífilis, fazendo sem preservativo". Diante do exposto, a realização do sexo oral sem preservativo, torna o corpo das pessoas mais vulnerável as IST, como ocorrido com Zebrinha que se contaminou com a sífilis.

\begin{tabular}{lllll}
\hline Hygeia Uberlândia - MG $\quad$ Edição especial: X GeoSaude & Fev./2022 & p. 23-33 Página 29
\end{tabular}


Em relação a Borboleta-oitenta, que trabalha na prostituição, ela compartilhou que possui relações sexuais desprotegidas com alguns clientes no cinema pornô, onde ela trabalha. Todavia, com o namorado, ela afirmou que usa o preservativo:

Eu, com meu namorado, a gente sempre usa camisinha. Isso assim oh, a partir do momento dito assim: 'eu trabalho com programa, eu sou uma bomba relógio'. Ah e que nem ali [no cinema pornô], é... tenho minhas escorregadinhas, vou te falar, não sou perfeita. Teve vezes, acontecer de estourar a camisinha. Teve vezes do cara que não quer [usar] camisinha. Eu viro pra meu companheiro, eu falo assim: 'oh, bom, você vai arriscar?'. Que o trabalho aqui é um perigo, né? Eu to falando por mim (BORBOLETA-OITENTA, 33 ANOS, ENTREVISTA REALIZADA EM 17/01/2017).

Dentre as práticas do cuidado de si mais utilizadas pelas travestis que se prostituem em São Paulo/SP, como mencionado por Pelúcio (2009), destaca-se o uso dos preservativos nos momentos do sexo oral e anal. Entretanto, os preservativos são descartados nas relações sexuais que as travestis praticam com os namorados e/ou maridos. Pelúcio (2009) demonstra que o hábito das travestis não utilizarem preservativos com os seus namorados e/ou maridos torna-se preocupante no sentido de que elas trocam de parceiros com uma certa frequência, resultando em práticas sexuais desprotegidas com um grande número de pessoas.

Assim como Monarca e Borboleta-oitenta, Imperatriz-rosa socializou que, trabalhando com a prostituição, já se relacionou sexualmente sem o uso do preservativo. Nas palavras dela: "se eu falar pra você que eu sempre usei preservativo, vou estar mentido, entendeu? Vou estar mentindo" (IMPERATRIZ-ROSA, 37 anos, entrevista realizada em 22/04/2017). Contudo, em 2017, Imperatrizrosa se demonstrou sensibilizada em cuidar de si, afirmando que ela não se relaciona sexualmente sem o preservativo.

Por mais que eu faça programa, podem oferecer, pode oferecer bem a mais, o dobro do meu preço [e] eu não faço, porque minha saúde tá em primeiro 'local' (sic.) e o dinheiro não vai pagar minha saúde amanhã. Nada contra quem faz [sexo sem preservativo]. Você tem [o] seu livre arbítrio. Só que amanhã, depois, [tem] as consequências, né? Eu penso que saúde tá em primeiro lugar (IMPERATRIZ-ROSA, 37 ANOS, ENTREVISTA REALIZADA EM 22/04/2017).

Imperatriz-rosa ainda observa que além de existir travestis e mulheres transexuais que não usam o preservativo nas relações sexuais, existem travestis e mulheres transexuais que também não querem realizar o exame para identificar se possui ou não o vírus HIV. "Elas tem medo de falar, elas não gostam nem de tocar nesse assunto. 'Ai, vamos fazer o exame? Eu vou com você'. Elas não querem, entendeu?" (IMPERATRIZ-ROSA, 37 anos, entrevista realizada em 22/04/2017).

O medo em realizar o exame para identificar o vírus HIV é decorrente, segundo Tagliamento (2012), do estigma social que incide sobre a AIDS que, no final do século XX, existiu o preconceito equivocado de que toda pessoa portadora do vírus HIV fosse promíscua, tivesse relações sexuais desprotegidas e/ou fosse usuária(o) de drogas injetáveis. Além desse cenário, existia o preconceito de que o diagnóstico de ser portador(a) do vírus HIV fosse um atestado de morte.

No início do século XXI, no Brasil, durante as duas gestões dos governos do ex-presidente da república Luiz Inácio Lula da Silva (2003-2011), existiu um conjunto de políticas públicas como, por exemplo, o Plano Nacional de Enfrentamento da Epidemia de AIDS e das IST entre gays, Homens que fazem Sexo com Homens (HSH) e travestis (BRASIL, 2008), que objetivou combater os estigmas sociais incidentes nos corpos portadores do vírus HIV, e combater novas infecções com base na distribuição gratuita de preservativos nos espaços formais de saúde e nas ONG's.

Todavia, analisando o 'uso do preservativo' como uma prática do 'cuidado de si' na prevenção das IST, foi possível identificar que essa prática nem sempre é eficaz. Ípsilon compartilhou que mesmo usando o preservativo, se infectou com o vírus HIV, pois o preservativo estourou durante uma relação sexual, como é demonstrado na sequência:

Chegou um tempo que eu 'tava' (sic.) sentindo algo diferente em mim. Eu 'tava' (sic.) emagrecendo demais. 'Tava' (sic.) sentindo algumas... algo diferente em mim, né? E daí, como eu, era frequentemente ir fazer esses exames [de HIV], eu fui... até que deu positivo, mas só que eu já sabia de quem que eu peguei, que estourou o preservativo, né? Só que foi uma pessoa que eu confiei e ele não me falou, né? Se não, eu tinha me cuidado mais, e daí que deu positivo. Por isso que eu tô tomando [coquetel] (ÍPSILON, 40 ANOS, ENTREVISTA REALIZADA EM 24/02/2017).

\begin{tabular}{lllll}
\hline Hygeia Uberlândia - MG $\quad$ Edição especial: X GeoSaude $\quad$ Fev./2022 & p. 23-33 Página 30
\end{tabular}


O relato de Ípsilon indica que o uso do preservativo não deve ser interpretado como uma prática singular no cuidado de si na prevenção das IST, pois aliado ao uso do preservativo, a travesti e/ou a mulher transexual também deve realizar regularmente 'exames' (13\%) clínicos para identificar se é ou não portadora do vírus HIV e outras IST, pois o problema não é somente ser portadora do vírus HIV, e sim desconhecer que é portadora do vírus HIV e não realizar acompanhamento médico, tratamento medicamentoso adequado e ter relações sexuais desprotegidas com outras pessoas.

Pantera, Pequena-zebra e Bicuda afirmaram que elas priorizam se relacionar sexualmente somente com preservativo. No caso de Bicuda, ela destacou que mesmo tendo um parceiro fixo, ela prioriza o cuidado de si com o uso do preservativo:

Atualmente o que acaba me afetando mais, que tá em 'epidemia' (sic.), é a questão das 'Doenças Sexualmente Transmissíveis' (sic.), né? As infecções que na hora são... chamam de Infecções Sexualmente Transmissíveis (IST), sempre se cuidando. Eu, como tenho namorado, mesmo com ele, nós sempre fazemos sexo com preservativo. Sempre se cuidando, né? É... e sempre fazendo exames de rotina (BICUDA, 28 ANOS, ENTREVISTA REALIZADA EM 09/02/2017).

A prática do uso do preservativo aliada a realização de exames, como compartilhado por Bicuda, também foi mencionada por Imperatriz-rosa, Ípsilon, Casca-de-limão e Alemã. Para elas, praticar o cuidado de si, envolve a realização de exames para identificar se elas são ou não portadoras de alguns vírus como, por exemplo, o HIV e a Hepatite:

Então, quando eu fiz esse exame e vi que o pior lá, que o HIV [e] Hepatite deram negativo, eu nasci de volta, entendeu? Então agora eu me cuido bem mais, né? (IMPERATRIZ-ROSA, 37 ANOS, ENTREVISTA REALIZADA EM 22/04/2017).

Qualquer coisa que eu vejo de diferente em mim, assim, dores, né? Eu já corro no médico. Já pede um exame assim, ainda mais agora que o meu ex-namorado, que eu era... frequentemente eu fazia esses exames de HIV, então, eu fazia umas 2-3 vezes por ano, entendeu? (ÍPSILON, 40 ANOS, ENTREVISTA REALIZADA EM 24/02/2017).

Eu já fiz 7 exames de HIV, particular, entendeu? [...] Só quando, assim, como o infectologista falava: 'olha gente, se você tem uma relação de risco só vai aparecer no seu organismo após 3 meses. Não adianta você sair com uma pessoa hoje, não usou preservativo, ficar louco e fazer o exame amanhã, porque acha que vai estar contaminada, né?'. A pessoa pode estar contaminada, mas só vai aparecer no seu organismo após 3 meses. Então, cuide-se, né? Pra não, né? pra não ficar... porque a pessoa fica louca querendo saber o que aconteceu logo. Fica até depressiva, sem dormir, tudo até dar os 3 meses pra fazer o exame. Aí, daí não dá né? Aí depois vai fazer a mesma coisa. A pessoa tem que errar uma vez só. Assim, não ficar errando, né? Permanecer errando sempre não dá (ALEMÃ, 48 ANOS, ENTREVISTA REALIZADA EM 18/04/2017).

Segundo Bicuda, a realização de exames faz parte do processo de cuidar de si. Para ela:

Entendo por saúde, que a pessoa tem que estar ciente dos riscos, né? E estar ciente que ela também tem que sempre fazer exames mensais, não esperar que de repente chegue de você pegar algo ou ter alguma coisa pra se correr atrás (BICUDA, 28 ANOS, ENTREVISTA REALIZADA EM 09/02/2017).

Como mencionado por Bicuda, Pantera socializou que ela realiza exames de sangue para cuidar de si:

De maneira geral? É que nem estávamos falando já hoje, fazendo exames, né? No caso sanguíneo, sempre 'to' fazendo, indo no médico, porque eu tenho bronquite e eu já tive problema pulmonar e eu não posso pegar pneumonia, sabe? Eu tenho um problema bem sério no pulmão (PANTERA, 32 ANOS, ENTREVISTA REALIZADA EM 23/04/2017).

A prática do 'cuidado de si' na realização de 'exames', como evidenciado nas falas analisadas, indica que as travestis e mulheres transexuais realizam os exames de sangue para saber se são ou não portadoras de algum vírus que pode adoecer seus corpos.

\section{CONSIDERAÇÕES FINAIS}

Considerando a questão central desta reflexão teórica, 'quais são as práticas do cuidado de si executadas por travestis e mulheres transexuais, na prevenção das Infecções Sexualmente Transmissíveis (IST), nos municípios de Curitiba e Ponta Grossa, Paraná?', foi possível compreender

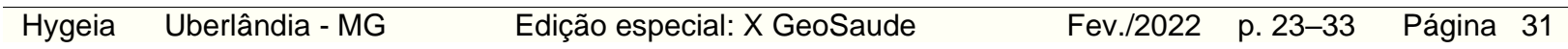


que as práticas do cuidado de si envolvem o uso de preservativos, realização de exames e tratamento PrEP e PEP.

Contudo, em decorrência do estigma que incide sob os corpos portadores das IST, sobretudo o HIV/AIDS, existem travestis e mulheres transexuais que possuem o receio de realizar os exames de sangue, para investigar se possuem ou não a doença. Esse cenário agrava a pandemia de HIV/AIDS, pois podem existir pessoas que imunodepressoras que desconhecem o estado de saúde.

Diante do contexto analisado, torna-se imperativo que exista a manutenção de políticas de saúde pública que estimulem a realização de exames e o tratamento das IST em grupos sociais vulneráveis, principalmente para travestis e mulheres transexuais.

\section{REFERÊNCIAS}

ANTRA - Associação Nacional de Travestis e Transexuais. BENEVIDES, Bruna; NOGUEIRA, Sayonara Naider Bonfim (org.). Dossiê assassinatos e violência contra travestis e transexuais brasileiras em 2019. 2020. Disponível em: <

https://antrabrasil.files.wordpress.com/2020/01/dossic3aa-dos-assassinatos-e-da-violc3aancia-contrapessoas-trans-em-2019.pdf > Acesso em: 05/05/2021.

BARDIN, Laurence. Análise de conteúdo. 1aㅡ edição. São Paulo/SP: Edições 70, [1977] 2016.

BENATO, Ana Paula; BRAGA, Ramon de Oliveira Bieco. Transfobia no espaço escolar: intolerância contra os corpos travestis e transexuais no Brasil. In: Anais do IV Simpósio Internacional Desfazendo Gênero: corpos dissidentes, corpos resistentes: do caos à lama. Recife/PE: Realize, 2019. v. 01. p. 01-10.

BENEDETTI, Marcos Renato. Toda feita: o corpo e o gênero das travestis. Rio de Janeiro/RJ: Garamond Universitária, 2005.

BRAGA, Ramon de Oliveira Bieco. Espaço e as práticas do cuidado de si, na relação saúde/doença do corpo das travestis e mulheres transexuais em Curitiba e Ponta Grossa, Paraná. $438 \mathrm{f}$. Tese (Doutorado em Geografia), Universidade Estadual de Ponta Grossa, Ponta Grossa/PR, 2020.

BRAGA, Ramon de Oliveira Bieco. Interdição espacial das Travestis no acesso aos serviços de saúde em Curitiba/PR, Brasil. In: Anais do XIII Mundos de Mulheres e Fazendo Gênero XI.

Florianópolis/SC, 2017. v. Único. p. 01-10.

BRAGA, Ramon de Oliveira Bieco; ORNAT, Marcio José. Relações entre saúde e doença nas espacialidades discursivas das mulheres trans e travestis em Ponta Grossa, Paraná. TERR@ PLURAL (UEPG. ONLINE), v. 13, p. 189-207, 2019. https://doi.org/10.5212/TerraPlural.v.13i1.0012

BRAGA, Ramon de Oliveira Bieco; ORNAT, Marcio José. Travestis, Mulheres e Homens Transexuais nas Unidades de Saúde em Curitiba, Paraná: Uma Leitura Crítica a partir da Interdição Espacial. In: MOTA, Adeir Archanjo da; ROMA, Cláudia Marques. (Org.). Contextos Geográficos, Saúde Mental e Violências: Das Pessoas ao Território e do Território às Pessoas. Dourados/MS: UFGD, 2020, p. 135-152.

BRASIL. MS - Ministério da Saúde. Doenças de Condições Crônicas e Infecções Sexualmente Transmissíveis. Preservativos. 2019b. Disponível em: < http://www.aids.gov.br/pt-br/publicogeral/prevencao-combinada/preservativo > Acesso em: 05/05/2021.

BRASIL. Ministério da Saúde - MS. PEP (Profilaxia Pós-Exposição ao HIV). 2020a. Disponível em: < http://www.aids.gov.br/pt-br/publico-geral/prevencao-combinada/pep-profilaxia-pos-exposicao-ao-hiv > Acesso em: 05/05/2021.

BRASIL. MS - Ministério da Saúde. Doenças Sexualmente Transmissíveis. 2015. Disponível em: < http://bvsms.saude.gov.br/dicas-em-saude/2063-doencas-sexualmente-transmissiveis-dst $>$ Acesso em: 05/05/2021.

BRASIL. Ministério da Saúde - MS. Profilaxia Pré-Exposição (PrEP). 2020b. Disponível em: < http://www.aids.gov.br/pt-br/publico-geral/prevencao-combinada/profilaxia-pre-exposicao-prep > Acesso em: 05/05/2021.

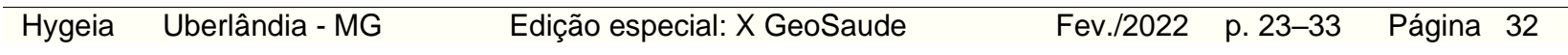


BRASIL. MS - Ministério da Saúde. Saúde da população de gays, lésbicas, bissexuais, travestis e transexuais. Revista Saúde Pública, v.03, n.42, p.570-573, 2008. https://doi.org/10.1590/S0034$\underline{89102008000300027}$

BUTLER, Judith. Problemas de gênero: feminismo e subversão da identidade. $11^{\text {a }}$ edição. Rio de Janeiro: Civilização Brasileira, [2003] 2016.

CABRAL, Vinicius; ORNAT, Marcio Jose; SILVA, Joseli Maria. As relações entre espaço, violência e a vivência travesti na cidade de Ponta Grossa - Paraná - Brasil. Caderno Prudentino de Geografia, Presidente Prudente/SP, n.35, volume especial, p. 118-135, 2013.

CARNEIRO, Marcia Tobias. Vivências espaciais da saúde no grupo de travestis e transexuais na cidade de Ponta Grossa - Paraná. 109 f. Dissertação (Mestrado em Geografia) - Departamento de Geografia, Universidade Estadual de Ponta Grossa, Ponta Grossa/PR, 2014.

GOODMAN, Leo. Snowball sampling. Annals of Mathematical Statistics, n.01, v.32, p.148-170, 1961. https://doi.org/10.1214/aoms/1177705148

KULICK, Don. Travesti: prostituição, sexo, gênero e cultura no Brasil. Rio de Janeiro/RJ: FIOCRUZ, 2008.

ORNAT, Marcio Jose. Território descontínuo e multiterritorialidade na prostituição travesti através do sul do Brasil. $278 \mathrm{f}$. Tese (Doutorado em Geografia) - Departamento de Geografia, Universidade Federal do Rio de Janeiro, Rio de Janeiro/RJ, 2011.

PELÚCIO, Larissa. Abjeção e desejo: uma etnografia travesti sobre o modelo preventivo de AIDS. São Paulo/SP: Annablume, 2009.

PERES, Wiliam Siqueira. Travestis: corpo, cuidado de si e cidadania. In: Anais do Fazendo Gênero 8: corpo, violência e poder. Florianópolis/SC, 2008. p. 01-07.

PONTES, Júlia Clara de; SILVA, Cristiane Gonçalves da. Cisnormatividade e passabilidade: deslocamentos e diferenças nas narrativas de pessoas trans. Periódicus, n. 08, v. 01, p. 396-417, 2018. https://doi.org/10.9771/peri.v1i8.23211

SARTI, Cynthia. Corpo e doença no trânsito de saberes. RBCS, v. 25, n. 74, p. 77-90, out. 2010. https://doi.org/10.1590/S0102-69092010000300005

SILVA, Hélio Raymundo Santos. Travestis - entre o espelho e a rua. Rio de Janeiro/RJ: Rocco, [1993] 2007.

SILVA, Irene de Jesus; OLIVEIRA, Marília de Fátima Vieira de; SILVA, Silvio Éder Dias da; POLARO, Sandra Helena Isse; RADUNZ, Vera; SANTOS, Evanguelia Kotzias Atherino dos; SANTANA, Mary Elizabeth de. Cuidado, autocuidado e cuidado de si: uma compreensão paradigmática para o cuidado de enfermagem. Rev. Esc. Enferm., USP, v. 43, n. 03, p. 697-703, 2009.

https://doi.org/10.1590/S0080-62342009000300028

TAGLIAMENTO, Grazielle. (In)visibilidades caleidoscópicas: a perspectiva das mulheres trans sobre o seu acesso à saúde integral. 166 f. Tese (Doutorado em Psicologia), Universidade de São Paulo, São Paulo/SP, 2012.

TGEU - Transgender Europe. Actualización TDoR 2017 TMM. Nota de Prensa. 2017. Disponível em: $<$ https://transrespect.org/wp-content/uploads/2017/11/TvT TMM TDoR2017 PR ES.pdf > Acesso em: 05/05/2021.

VENTURA, Miriam; SCHRAMM, Fermin Roland. Limites e possibilidades: do exercício da autonomia nas práticas terapêuticas de modificação corporal e alteração da identidade sexual. Physis - Revista de Saúde Coletiva, Rio de Janeiro/RJ, v. 19, n. 01, p. 65-93, 2009. https://doi.org/10.1590/S0103$\underline{73312009000100005}$ 